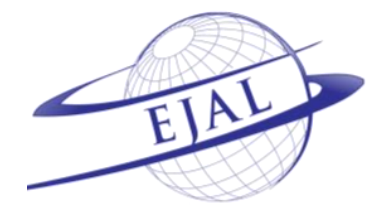

Available online at www.ejal.eu

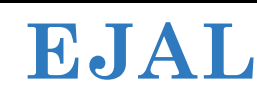

Eurasian Journal of

Eurasian Journal of Applied Linguistics 3(2) (2017) 75-88

Applied Linguistics

\title{
The Effect of Data-driven Learning on EFL Students' Acquisition of Lexico-grammatical Patterns in EFL Writing
}

\author{
Maide Yılmaz a * (D) \\ ${ }^{a}$ Gazi University, School of Foreign Languages, Ankara 06830, Turkey
}

Received 13 February 2017 | Received in revised form 1 October 2017 | Accepted 2 October 2017

\begin{abstract}
The present study investigated whether and to what extent data-driven learning (DDL) can improve the lexicogrammatical use of abstract nouns in L2 writing. A corpus composed of 40 graded readers was compiled to make the learners do concordance learning activities, and 30 Turkish English as a Foreign Language (EFL) students at Gazi University School of Foreign Languages were assigned to a control group or an experimental group. At the prewriting stage, both the control group and the experimental group were given a list of ten abstract nouns and wrote stories without using dictionaries. Then, the errors they made while writing were underlined. While the experimental group was taught how to use a concordancing tool and studied on concordance lines from the corpus of graded readers to correct their errors, the control group just had dictionaries to consult and worked on their errors. Afterwards, both groups wrote their second stories using the same words given in the pre-test. The texts written in the pre-test and post-test were analysed and compared between groups. The results indicated that the experimental group, as compared with the control group, used a greater variety of collocational and colligational patterns and had fewer linguistic errors while using the abstract nouns. Finally, a questionnaire was administered to the experimental group and the results obtained from it showed that students were very positive about the use of DDL and concordance activities. Also, they were willing to use DDL activities in the future.
\end{abstract}

(C) 2017 EJAL \& the Authors. Published by Eurasian Journal of Applied Linguistics (EJAL). This is an open-access article distributed under the terms and conditions of the Creative Commons Attribution license (CC BY-NC-ND) (http://creativecommons.org/licenses/by-nc-nd/4.0/).

Keywords: Data-Driven Learning; Corpus; EFL Writing; Lexico-Grammatical Patterns, Concordance

\section{Introduction}

EFL writers often have difficulties with limited vocabulary or with vocabulary which has been partially learned and research has shown that lack of vocabulary contributes to writing difficulty for foreign language learners (e.g. Astika, 1993). That is, vocabulary is one of the most important features that determine writing quality (Walters \& Wolf, 1996).

Data-driven learning (DDL) is a teaching model in which corpus is used by learners with the guidance of teachers for language learning purposes. Learners use a computer search engine or a web tool to find the course content and to do appropriate

* Maide Yllmaz. Tel.: 05545848171

E-mail address: maideyilmaz@gazi.edu.tr

http://dx.doi.org/... 
exercises. Recently, DDL has been considered as a way of improving English as a Foreign Language (EFL) learners' vocabulary and strengthening their lexicogrammatical knowledge. By this way, it contributes to the improvement in overall writing quality of EFL learners. This teaching model encourages students to find vocabulary in context.

DDL affects language learning in several ways (Johns \& King, 1991). It helps the learner see patterning in the target language. Learners can recover the rules from the examples and reach generalizations with the aid of this teaching method. Thus, it supports bottom-up inductive language learning. The data has primary importance, and it is not possible for the teacher to know in advance exactly what the learners will discover. Thus, it creates challenge and supports discovery learning. By this way, data-driven learning process encourages students to learn self-management and selfassessment. In DDL approach the learner's own discovery of grammar is at the centre of language-learning. Mostly, that discovery is based on evidence from authentic language use and authentic language environment which can improve the efficiency of language learning. Moreover, in DDL the teacher is the director and coordinator of student-initiated research. They have to organize and guide students to carry out selfaccess learning.

Pedagogical corpus applications can be divided into two categories as indirect applications and direct applications (Römer, 2008). Indirect applications refer to the use of corpora by researchers and materials writers. Direct applications refer to the use of corpora by teachers and learners to explore corpus themselves (DDL). There has been more interest on the latter in recent studies.

Studies on DDL activities in writing have had different focuses. Some of them investigated student perceptions of corpus use in writing (Charles, 2012; Gaskell \& Cobb, 2004; Mizumoto, Chujo, \& Yokota, 2016; O’Sullivan \& Chambers, 2006; Sun, 2007; Yoon \& Hirvela, 2004). Yoon and Hirvela (2004) conducted a study on corpus use in ESL academic writing courses. They examined students' corpus use behaviour and their perceptions of corpora as a writing tool. The results indicated that the students found the corpus approach beneficial to the development of L2 writing skill and they increased confidence toward L2 writing. Sun (2007) created the Scholarly Writing Template (SWT) which included the information template that gives an outline of moves commonly used in research papers, the language template that consisted of a corpus of typical phrases and sentences collected by the students themselves, and a concordancer to search the corpus. The results showed that the students had very positive attitudes toward the SWT especially for writing skill development, sentence structure, and idea development.

Some researchers preferred focusing on the effects of DDL on self-correction (Gaskell \& Cobb, 2004; Todd, 2001; Tono, Satake, \& Miura, 2013; Yoon \& Jo, 2014). Todd (2001) investigated induction, the use of concordances, and self-correction. In the study, lexical items causing errors in writing were identified and the participants selfcorrected their errors using small concordances of the lexical items from the Internet 
by inducing patterns. The results showed that students were able to induce valid patterns from their self-selected concordances and make valid self-corrections of their errors.

Most studies have aimed to investigate the effects of DDL on learners' vocabulary and grammar (Coxhead \& Byrd, 2007; Huang, 2014; Liu \& Jiang, 2009; Mizumoto \& Chujo, 2016; Ucar \& Yükselir, 2015; Varley, 2009; Vyatkina, 2016; Yunus \& Awab, 2014). Liu and Jiang (2009) examined the effects of integrating corpus and contextualized lexico-grammar in foreign and second language teaching. The analysis of their data revealed that learners improved their command of lexico-grammar, increased critical understanding of grammar, and enhanced discovery learning skills. However, the study brought to light that corpus-based lexico-grammar analysis caused some difficulties for many students.

Mizumoto and Chujo (2016) examined the relationship between one type of datadriven learning (DDL) and inductive-deductive learning styles and found that the participants improved their grammar significantly after teacher-led guided DDL induction. Their findings pointed out that guided DDL type induction may be beneficial for both deductive and inductive learners irrespective of their learning styles.

Ucar and Yükselir (2015) investigated the impacts of corpus-based activities on verb-noun collocation learning in EFL classes. Their study had an experimental design and consisted of 30 participants. The experimental group was taught verbnoun collocations through corpus-based materials, and the control group learnt collocations via conventional methods. They found a statistically significant difference between the experimental and the control group which showed that corpus-based activities had a significant impact on the teaching of verb-noun collocations in EFL classes.

Also, Yunus and Awab (2014) aimed at investigating the impact of DDL instruction on the production of colligations of prepositions. 40 participants took part in the study. The experimental group was treated with concordance printouts of the colligational patterns and the DDL approach while the control group was treated with the non-DDL module and taught deductively. The results showed that the students in the DDL group performed significantly better than the students in the control group. Vyatkina (2016) also explored the effects of DDL of German lexico-grammatical constructions by comparing the effects of computer-based and paper-based DDL activities. The results showed that both DDL types were effective for learners, and overall learner proficiency increased. Moreover, learners expressed their desire to use DDL for independent learning in the future.

Similar to the present study, Huang (2014) investigated whether and to what extent data-driven learning (DDL) activities can improve the lexico-grammatical use of abstract nouns in L2 writing. He compiled a topic-based corpus to develop concordance learning activities and conducted an experimental study including 40 Chinese students. The study consisted of a prewriting stage in which both the control 
and the experimental groups were given a list of five abstract nouns and wrote essays including these words. Paper-based concordance lines were given to the experimental group while the control group consulted dictionaries for the usage of the words. The written texts of the pre-test, immediate post-test, and delayed post-test were analysed and compared between and within groups. The results of the study revealed that the written output by the experimental group had a higher variety of collocational and colligational patterns and fewer linguistic errors in using the target abstract nouns. Also, post-experiment learning journals and questionnaires were administered to the experimental group and the results revealed that concordance activities helped students learn the lexical collocations and prepositional colligations of the target words, and by this way, they contributed to accuracy and complexity in their productive language.

The present study was designed to investigate the effects of DDL on vocabulary use

in L2 writing and to reveal the perceptions of EFL learners on DDL. To shed light on these issues, the following questions were asked:

1. Can DDL help EFL learners improve their lexico-grammatical use of abstract nouns in their writing?

2. What are the perceptions of EFL learners of the effect of DDL on their vocabulary learning and vocabulary use in writing?

\section{Method}

\subsection{Setting and Participants}

Thirty preparatory school students at Gazi University in Ankara participated in this study. Their overall English proficiency level was pre-intermediate according to the proficiency test conducted at the beginning of 2016-2017 academic year. The participants were chosen based on convenience sampling. They were assigned to a control group or an experimental group each with fifteen students. Of thirty students, 17 were female and 13 were male.

\subsection{Procedure}

Although many studies on DDL are based on a reference corpus, for this study a corpus was compiled consisting of forty graded readers on various topics and of various genres. The main reason for that was the level of the students. A reference corpus like BAWE includes texts written by native speakers and includes too much and high-level academic vocabulary. It would make concordancing much more difficult for the students at pre-intermediate level. Thus, a new corpus which included 604.074 tokens at their level of English was created. Then, based on the wordlist which was reached with the aid of the corpus analysis tool AntConc 3.4.4 (for Windows), ten most 
frequently used abstract nouns were chosen (each word occured at least eleven times). They were argument $(f=32)$, attention $(f=36)$, difficulty (17), excitement $(f=33)$, importance $(f=11)$, mystery $(f=26)$, permission $(f=18)$, pleasure $(f=24)$, promise $(f=$ 14) and silence $(f=97)$.

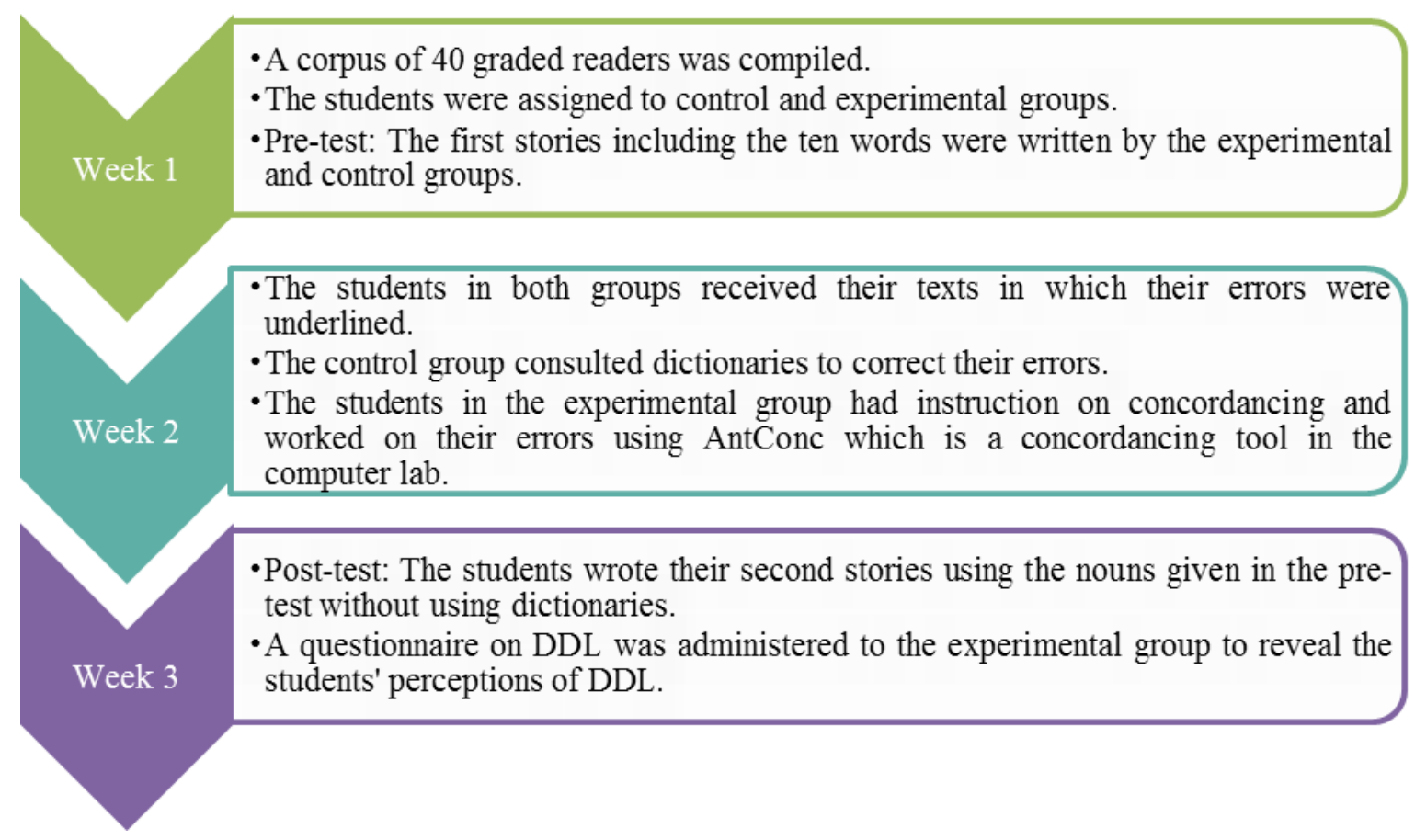

Figure 1 Procedure of the study

As Figure 1 shows, in the first week, the participants in the experimental and the control group were asked to write stories using the ten words without changing the forms as a pre-test. They were free to write on any topics or in any genres. They were not allowed to use dictionaries while writing. A story writing task was chosen for the study because of two reasons. First, it is a task given in Preliminary English Test (PET) which is an English language examination provided by Cambridge English Language Assessment for pre-intermediate learners. Also, the participants of the study had not known how to write an essay. They had learnt writing a paragraph, but it was very difficult to use all ten words in a short paragraph.

In week two, the students in both groups received their texts they wrote in the pretest. No feedback related to the ten nouns used in the stories was given except for underlined errors. After that, each student in the control group studied on his/her errors using dictionaries. However, the students in the experimental group had instruction on how to use AntConc and concordancing for two hours. Then, they went to the computer lab, studied on their underlined errors using this program and the concordances from e-books and they tried to self-correct their errors. The aim of this 
error correction stage was to make the students notice the sources of their errors and learn about the correct forms of the vocabulary items, collocational and colligational patterns and correct their errors with the help of concordances.

In the third week, the students in the control group and the experimental group wrote their second stories as a post-test. All the participants were required to use the same ten nouns as in the pre-test in their writing. They were not allowed to use dictionaries as in the pre-test. After the post-test, a questionnaire (Huang, 2014) was administered to the experimental group during the class to evaluate the DDL activities.

\subsection{Data analysis}

In this study, the effects of the DDL activities on learners' writing were investigated by analysing student essays and the data obtained from students' questionnaires based on their perceptions. As mentioned above, students' stories were analysed. Two non-native English teachers evaluated the students' use of the target nouns, and they categorized them as appropriate and inappropriate. The use of the nouns falling into the category inappropriate was characterized as errors. They agreed on $98 \%$ of the categorizations. The categorization was completed after reaching an agreement on the category of the use. In addition to the analysis of the use of the ten nouns, students were given questionnaires on their perceptions of DDL activities in writing. The questionnaire was prepared by Huang (2014). Analysis showed that the questionnaire had internal reliability $(\alpha=0.82)$. The means and standard deviations were calculated using the Statistical Package for the Social Sciences (SPSS 20.0). The students' responses for the questionnaire items were coded into three categories: "helpful", "not helpful", and "no opinion" by placing all the positive answers (5 "somewhat agree", 6 "agree", and 7 "strongly agree) into the "helpful" category, and all negative answers (1 "strongly disagree", 2 "disagree", 3 "somewhat disagree") into the "not helpful" category as in Huang's study (2014).

\section{Results}

\subsection{Accuracy}

The control group and the experimental group were compared in terms of error-free ratios and the use of the abstract nouns. The control group and the experimental group had similar error-free ratios in terms of the use of the ten target nouns $(54 \%$ and $56 \%$ respectively) in the pre-test. However, in the post-test, while the experimental group's error-free ratios increased to $85 \%$ the control group's error-free ratios only rose to $63 \%$.

As in Huang's study (2014), the use of the target nouns by the experimental group was investigated and categorized into three types: positive change, negative change, and no change. When the students used the nouns inappropriately in the pre-test, but they used them correctly in the post-test, their second use was described as "positive 
change" and "negative change" described the appropriate use of the nouns in the pretest but inappropriate uses in the post-test. Also, when the nouns were used inappropriately in the pre-test and the post-test, they were described as "no change". The analysis showed that the instances of positive change (52) were much more than negative change (9) and no change (14). Examples of each category can be seen in Table 1.

\subsection{Complexity}

The control group and the experimental group were compared in terms of the use of lexico-grammatical patterns of the nouns in the post-test. As can be seen in in Figure 2 , nine of the target nouns were used in a variety of grammatical patterns by the experimental group. Only the grammatical patterns of importance were equal in both experimental and control groups. The noun was used in two patterns: 1) V + importance (by collocating know, notice, have, attach, realize and give by the experimental group and understand, have, think about, give and realize by the control group) and Importance + copular verb BE as subject (The importance of this device is that it checks if someone is at home.).

Table 1 Examples of positive change, no change and negative change

\begin{tabular}{|c|c|c|c|}
\hline Student & Changes & Pre-test & Post-test \\
\hline S3 & Positive change & This excitement can read at his face. & $\begin{array}{l}\text { Burak's body was shaking with } \\
\text { excitement. }\end{array}$ \\
\hline $\mathrm{S} 4$ & Positive change & He attacked my attention. & $\begin{array}{l}\text { Everyone congratulated me, but I } \\
\text { didn't pay any attention to } \\
\text { anyone }\end{array}$ \\
\hline S7 & Positive change & Sara was silence. & I looked at them in silence. \\
\hline S10 & Positive change & I did a promise to my family. & $\begin{array}{l}\text { Mine, as I made a promise, is to } \\
\text { share this tale of family love and } \\
\text { loss. }\end{array}$ \\
\hline S14 & Positive change & There was a importance situation. & $\begin{array}{l}\text { Some things in life had a } \\
\text { different importance for him. }\end{array}$ \\
\hline S11 & Negative change & $\begin{array}{l}\text { I wanted to save him but I had no } \\
\text { permission to do it }\end{array}$ & $\begin{array}{l}\text { I did not give permission you to } \\
\text { do it. }\end{array}$ \\
\hline S12 & No change & $\begin{array}{l}\text { I have been a doctor for } 17 \text { years. } \\
\text { Until this day I didn't live any } \\
\text { argument. }\end{array}$ & $\begin{array}{l}\text { My princess girl! I know } \\
\text { sometimes we lived some } \\
\text { arguments. }\end{array}$ \\
\hline
\end{tabular}

As for the noun argument, while there are two patterns $(\mathrm{V}+$ argument and copular verb $\mathrm{BE}+$ argument $)$ in the control group's stories, four different patterns $(\mathrm{V}+$ argument, copular verb $\mathrm{BE}+$ argument, $\mathrm{N}+$ argument (passive) and argument $+\mathrm{N}$ ) were found in the experimental group's stories. Moreover, the experimental group tended to use varied adjectives to modify argument (a passionate argument, a violent argument, a huge argument etc.). Similarly, in the use of the noun difficulty, while the control group used two patterns $(\mathrm{V}+$ difficulty and copular verb $\mathrm{BE}+$ difficulty) the experimental group used four patterns $(\mathrm{V}+$ difficulty, copular verb $\mathrm{BE}+$ difficulty, difficulty $+\mathrm{PP}$ and $\mathrm{V}+$ difficulty (passive). Also, mystery was used in four different 
patterns $(\mathrm{V}+$ mystery, copular verb $\mathrm{BE}+$ mystery, mystery + copular verb $\mathrm{BE}$ and $\mathrm{PP}$ + mystery) in the experimental group's texts. However, the noun was used in two patterns (copular verb $\mathrm{BE}+$ mystery and $\mathrm{V}+$ mystery) by the control group. The nouns permission, pleasure and attention were used in three different patterns $(\mathrm{V}+\mathrm{N}, \mathrm{PP}+$ $\mathrm{N}$ and copular verb $\mathrm{BE}+\mathrm{N}$ ) in the experimental group's texts. However, they were used in two different patterns by the control group (permission: $\mathrm{V}+\mathrm{N}$ and $\mathrm{PP}+\mathrm{N}$; pleasure: copular verb $\mathrm{BE}+\mathrm{N}$ and $\mathrm{V}+\mathrm{N}$; attention: $\mathrm{V}+\mathrm{N}$ and $\mathrm{N}+\mathrm{V}$ ). For the word promise there were two patterns $(\mathrm{V}+$ promise and $\mathrm{PP}+\mathrm{N})$ in the experimental group and only one pattern $(\mathrm{V}+$ promise $)$ in the control group.

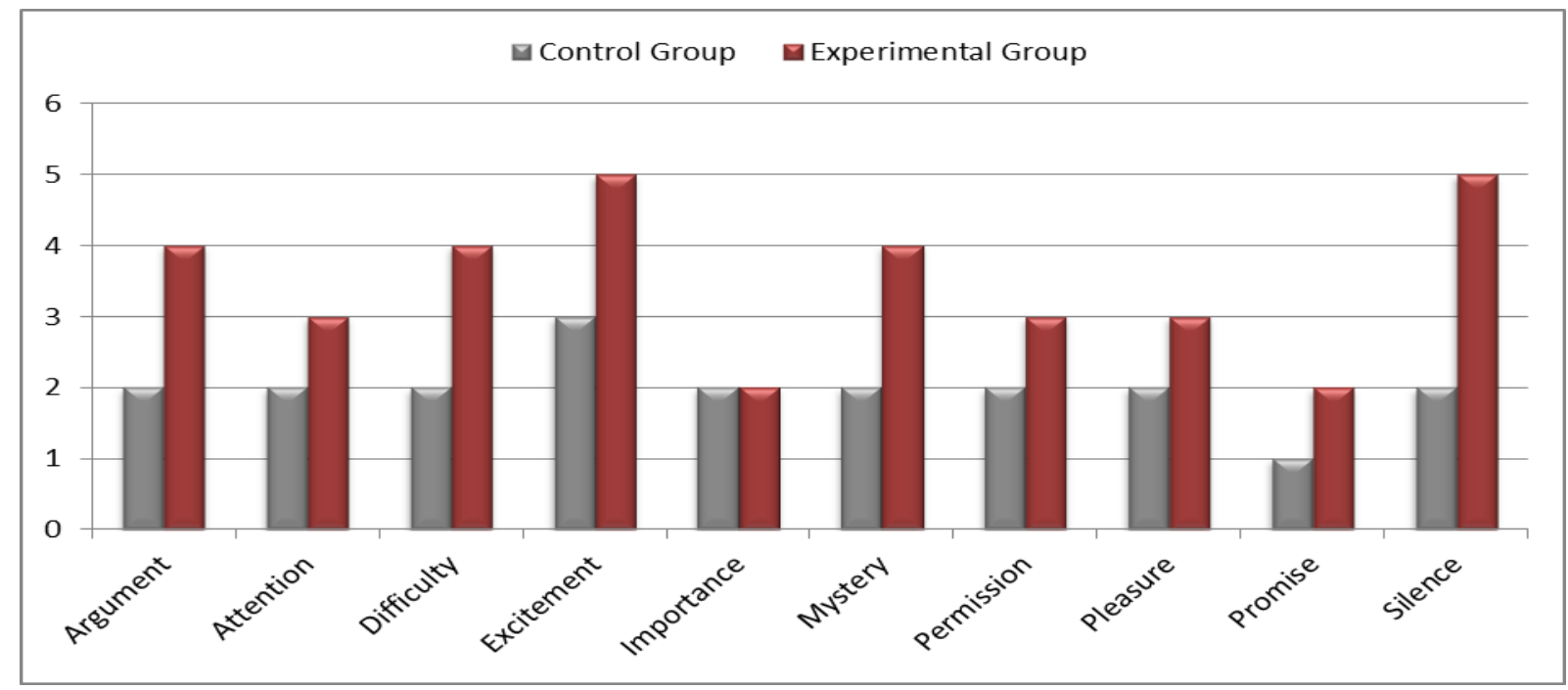

Figure 2 Distribution of lexico-grammatical patterns in the post-test

As mentioned above, there were some differences in terms of variety of the use of the eight nouns between the two groups, but the greatest differences were in the use of the nouns silence and excitement. Because of this reason examples of these two nouns are presented in Tables 3 and 4. Silence was used in five different patterns by the experimental group. Mostly, it was used as a subject complement (There was a strange silence.). Furthermore, it was used in $\mathrm{V}+$ silence pattern with different verbs to collocate with silence such as break, wait and live. Other patterns for silence were $\mathrm{PP}+$ silence, copular verb $\mathrm{BE}+$ silence, silence $+\mathrm{V}$ and silence $+\mathrm{NP}$. Moreover, the noun was used with various adjectives (sudden silence, awkward silence, strange silence, uncomfortable silence, breathless silence, unknown silence). Nevertheless, it was used in two patterns ( $\mathrm{PP}+$ silence and $\mathrm{V}+$ silence) by the control group.

Table 2 Lexico-grammatical patterns of silence in the post-test

\begin{tabular}{llll}
\hline & & Control group & Experimental group \\
$\begin{array}{l}\text { Functions } \\
\text { Object }\end{array}$ & $\mathrm{V}+\mathrm{N}$ & Patterns \\
& & $\begin{array}{l}\text { She was trying to hear the } \\
\text { silence. }\end{array}$ & He had to call for silence. \\
\hline
\end{tabular}




\begin{tabular}{|c|c|c|c|}
\hline \multirow[t]{3}{*}{ Subject } & $\mathrm{N}+\mathrm{V}$ & - & Silence fell over the crowd. \\
\hline & & & Silence spread out his realm. \\
\hline & $\mathrm{N}+\mathrm{V}$ (passive voice) & - & $\begin{array}{l}\text { The silence was broken by the } \\
\text { scream. }\end{array}$ \\
\hline $\begin{array}{l}\text { Subject } \\
\text { complement }\end{array}$ & Copular verb $\mathrm{BE}+\mathrm{N}$ & - & The silence was terrifying. \\
\hline Notional subject & There $\mathrm{BE}+\mathrm{N}$ & $\cdots$ & There was a moment's silence. \\
\hline \multirow[t]{2}{*}{ Complement of PP } & Prep. $+\mathrm{N}$ & $\begin{array}{l}\text { He achieved his goal in } \\
\text { silence. }\end{array}$ & $\begin{array}{l}\text { The sound echoed in the silence } \\
\text { of the night. }\end{array}$ \\
\hline & & & He sat in silence. \\
\hline
\end{tabular}

Similar to silence, excitement was used in a greater variety of grammatical patterns by the experimental group than by the control group. The experimental group used five grammatical patterns of excitement: 1) PP + excitement; 2) $\mathrm{V}+$ excitement; 3) excitement $+\mathrm{V}$; 4) excitement + copular verb $\mathrm{BE}$ and 5$)$ copular verb $\mathrm{BE}+$ excitement. However, the control group used the noun in three patterns: 1) excitement + copular verb $\mathrm{BE}$; 2) $\mathrm{PP}+$ excitement; 3) $\mathrm{V}+$ excitement.

The results indicated that to a large extent, the experimental group outperformed the control group in both areas of syntactic variations and correct grammar use.

Table 3 Lexico-grammatical patterns of excitement in the post-test

\begin{tabular}{|c|c|c|c|}
\hline & & Control group & Experimental group \\
\hline Functions & $\begin{array}{l}\text { Grammatical } \\
\text { structures }\end{array}$ & Patterns & Patterns \\
\hline \multirow[t]{2}{*}{ Object } & $\mathrm{V}+\mathrm{N}$ & I had a huge excitement. & $\begin{array}{l}\text { I could hardly control my } \\
\text { excitement. }\end{array}$ \\
\hline & & He couldn't hide his excitement. & $\begin{array}{l}\text { Don't ask questions! Feel the } \\
\text { excitement. }\end{array}$ \\
\hline \multirow[t]{3}{*}{ Subject } & $\mathrm{N}+\mathrm{V}$ & - & $\begin{array}{l}\text { A strange feeling of excitement } \\
\text { filled us. }\end{array}$ \\
\hline & & & $\begin{array}{l}\text { My amazement and excitement } \\
\text { grew. }\end{array}$ \\
\hline & $\begin{array}{l}\mathrm{N}+\mathrm{V} \\
\text { (passive voice) }\end{array}$ & - & $\begin{array}{l}\text { Excitement of him could be } \\
\text { understood. }\end{array}$ \\
\hline $\begin{array}{l}\text { Subject } \\
\text { complement }\end{array}$ & $\mathrm{N}+$ Copular verb $\mathrm{BE}$ & Excitement is a good thing. & It was a great excitement. \\
\hline \multirow[t]{3}{*}{$\begin{array}{l}\text { Complement of } \\
\text { PP }\end{array}$} & Prep. $+\mathrm{N}$ & $\begin{array}{l}\text { She looked at my eyes with } \\
\text { excitement. }\end{array}$ & Her eyes shone with excitement. \\
\hline & & & $\begin{array}{l}\text { Her face was pink with } \\
\text { excitement. }\end{array}$ \\
\hline & & & My body shook with excitement. \\
\hline
\end{tabular}

\subsection{Learner Perceptions on DDL}

The questionnaire focused on two aspects of the students' perceptions on DDL: (1) effects on vocabulary learning; and (2) the difficulties in doing the concordance activities. Before explaining students' perceptions on DDL, it is important to mention 
that it was the first time $86.7 \%$ of them had used concordances. As Table 4 indicates, most students (80\%) thought that DDL writing activities contributed their vocabulary learning. Moreover, for most of them, they helped them learn meaning of words (93.4\%), collocations (86.7\%) and usage of words (73.3\%). The average score regarding collocation learning $(M=6.00)$ ranked top among the categories However, they were not sure whether DDL activities were useful for learning grammatical patterns of the words $(46.7 \%)$.

In addition to the findings above, the students declared their opinions about the effectiveness of DDL activities on writing. While $60 \%$ of them believed concordance activities helped them improve their writing quality, $40 \%$ did not think that they affected their writing quality in a positive way. Also, $80 \%$ of the students thought due to concordance activities they gained some ideas for their writing. Most importantly, $86.7 \%$ of them stated that they could have more concordance activities in the future.

Table 4 Perceived effects on vocabulary learning

\begin{tabular}{|c|c|c|c|c|c|}
\hline G & Helpful & Not Helpful & No Opinion & Mean & S.D. \\
\hline Category & $\%$ & $\%$ & $\%$ & $\%$ & $\%$ \\
\hline Vocabulary learning in general & 80 & 20 & 0 & 5.53 & 1.64 \\
\hline Learning meaning of words & 93.4 & 6.7 & 0 & 5.66 & 1.11 \\
\hline Learning collocation & 86.7 & 13.3 & 0 & 6.00 & 1,73 \\
\hline Learning grammatical patterns of the words & 46.7 & 46.7 & 6.7 & 4.26 & 2.25 \\
\hline Learning the usage of words in writing & 73.3 & 26.7 & 0 & 5.00 & 1.60 \\
\hline
\end{tabular}

*1-3= disagree, $4=$ no opinion 5-7= agree

As shown in Table 5, there were some questions about the problems in doing the DDL activities (Table 4) in the questionnaire. 53.4\% of the students had difficulty in formulating the overall rules of the usage of the words. However, $66.7 \%$ of them did not believe that studying concordances was time-consuming. Furthermore, they did not have problems about unfamiliar vocabulary while they were doing concordance activities.

Table 5. Problems in doing the DDL activities

\begin{tabular}{|c|c|c|c|c|c|}
\hline \multirow{2}{*}{ Category } & Agree & Disagree & No Opinion & Mean & S.D. \\
\hline & $\%$ & $\%$ & $\%$ & $\%$ & $\%$ \\
\hline Time-consuming & 33.4 & 66.7 & 0 & 3.80 & 2.04 \\
\hline Unfamiliar vocabulary & 46.7 & 53.3 & 0 & 3.93 & 1.83 \\
\hline $\begin{array}{l}\text { Difficulty in formulating the overall } \\
\text { rules of the usage of the words }\end{array}$ & 53.4 & 46.6 & 0 & 3.66 & 1.71 \\
\hline
\end{tabular}

*1-3= disagree, $4=$ no opinion 5-7= agree 


\section{Discussion and Conclusion}

RQ1. Can DDL help EFL learners improve their lexico-grammatical use of abstract nouns in their writing?

This study was an example of a direct application of corpora (Römer, 2008) because it intended to explore the effects of the use of corpus by the students. The results obtained from the pre-test and the post-test were in line with the results of the studies conducted by Boulton (2009), Huang, (2014), Liu \& Jiang (2009) and showed that DDL can have a strong effect on learners' improvement in the use of lexicogrammatical patterns. The learners participating in this study corrected their lexical and grammatical errors through a learner based approach. They noticed the collocational patterns in the corpus on their own and also they generated more accurate and complex syntactic patterns. Although both the learners in the control and the experimental groups were familiar with the ten nouns and their meanings at the beginning of the study; they knew that they needed to use them with a noun, a determiner or an adjective, and they must be followed by a preposition phrase as a complement, their prior grammatical knowledge did not help them use the target nouns successfully in their stories. The correct use of the target nouns in the post-test by the experimental group showed that DDL provided the experimental with practical guidance and helped them improve their knowledge of lexico-grammatical patterns.

The control group and the experimental group had similar error-free ratios in terms of the use of the ten target nouns in the pre-test, but in the post-test, the experimental group had much fewer errors in their texts. Also, even though the experimental group used various patterns in the post test, the patterns used by the control group were limited. For instance, excitement was used in a greater variety of grammatical patterns by the experimental group than by the control group. The experimental group used five grammatical patterns of excitement: 1) PP + excitement; 2) $\mathrm{V}+$ excitement; 3) excitement $+\mathrm{V}$; 4) excitement + copular verb $\mathrm{BE}$ and 5) copular verb $\mathrm{BE}+$ excitement. However, the control group used the noun in only three patterns: 1) excitement + copular verb $\mathrm{BE}$;2) $\mathrm{PP}+$ excitement; 3) $\mathrm{V}+$ excitement. Moreover, while the control group preferred using simple patterns in the post test, the experimental group used more complex patterns. For example, the noun silence was used with various adjectives by the experimental group (sudden silence, awkward silence, strange silence, uncomfortable silence, breathless silence, unknown silence). That is, the results indicated that to a large extent, the experimental group outperformed the control group in both areas of syntactic variations and correct grammar use because of the use of DDL activities as in the studies of Huang (2014), Mizumoto and Chujo (2016), Ucar and Yükselir (2015), Vyatkina (2016), and Yunus and Awab (2014). 
RQ2: What are the perceptions of EFL learners of the effect of DDL on their vocabulary learning and vocabulary use in writing?

The results obtained from the questionnaire on the effectiveness of DDL confirmed the results mentioned above and showed that the participants were positive about the use of DDL activities in writing because they believed that DDL activities contributed to their vocabulary learning and use in writing. They thought DDL activities helped them learn the meaning of words, collocations, and usage of words. Thus, the results were mostly similar to the results of the previous studies on learner perceptions of DDL (e.g. Charles, 2012; Gaskell \& Cobb, 2004; Huang, 2014; Mizumoto et al., 2016; O'Sullivan \& Chambers, 2006; Sun, 2007; Yoon \& Hirvela, 2004). Similar to the study of Yoon and Hirvela (2004) the students found the corpus approach beneficial to the development of writing skill. Also, the results were in line with Vyatkina's study's results (2016) which showed that learners were willing to use DDL for independent learning in the future. Also, as in Sun's study (2007), the students had very positive opinions on the DDL activities for writing skill. However, although in Huang's study the participants thought DDL activities were useful for learning grammatical patterns of the words, the participants in this study were not sure about their usefulness in learning grammatical patterns. As in Liu and Jiang's study (2009), corpus-based lexico-grammatical analysis caused some difficulties for some students. In addition, contrary to Huang's study (2014), students did not believe that studying concordances was time-consuming. Furthermore, they did not have problems with unfamiliar vocabulary while they were doing concordance activities unlike the participants in his study.

\section{Limitations and Suggestions for Future Research}

The study showed that using DDL in the classroom may lead to progress in using vocabulary and improvement in lexico-grammatical knowledge. Also, the learners who participated in the study were content with the use of DDL and concordance activities. That is, the study confirmed the previous studies which had found the positive effects of DDL. However, this study included only 30 participants, so the results cannot be generalized. A bigger sample can produce more reliable results. Moreover, the learners in the experimental group had received limited instruction on the use of concordancing tool AntConc. It may be more helpful for the learners to learn how to use the tool more efficiently in a longer period. In addition, the study was a small scale experimental study and investigated the short-term effects of DDL on the acquisition of lexico-grammatical patterns in L2 writing within a fixed period of time. Furthermore, learners' knowledge was tested through a pre-test and a post-test because of time limitation. The results were limited as they only revealed the students were able to use the acquired patterns in their writing immediately after the treatment. Yet, this is not enough to find the improvement of learners' writing ability and retention. Thus, a longitudinal study on the effects of DDL on learning lexico- 
grammatical patterns may be more informative about the gradual improvement of learners.

\section{References}

Astika, G. (1993). Analytical assessments of foreign language students' writing. RELC Journal $24,61-71$.

Boulton, A. (2009). Testing the limits of data-driven learning: Language proficiency and training. ReCALL, 21(1): 37-54.

Charles, M. (2012). 'Proper vocabulary and juicy collocations': EAP students evaluate do-ityourself corpus-building. English for Specific Purposes, 31, 93-102

Coxhead, A., \& Byrd, P. (2007). Preparing writing teachers to teach the vocabulary and grammar of academic prose. Journal of Second Language Writing, 16, 129-147.

Gaskell, D., \& Cobb, T. (2004). Can learners use concordance feedback for writing errors? System 32 (3), 301-319.

Huang, Z. (2014). The effects of paper-based DDL on the acquisition of lexico-grammatical patterns in L2 writing. ReCALL, 26(2), 163-183.

Johns, T., \& King, P. (1991). Classroom concordancing. English Language Research Journal, 4, $47-63$.

Kamariah Y., \& Awab, S. (2014). The impact of data-driven learning instruction on Malaysian law undergraduates' colligational competence, Kajian Malaysia, 32(1), 79-109

Liu, D., \& Jiang, P. (2009). Using a corpus-based lexicogrammatical approach to grammar instruction in EFL and ESL contexts. Modern Language Journal, 93(i), 61-78.

Mizumoto, A., Chujo, K., \& Yokota, K. (2016). Development of a scale to measure learners' perceived preferences and benefits of data-driven learning. ReCALL, 28(2), 227-246.

Mizumoto, A., \& Chujo, K. (2016). Who is data-driven learning for? Challenging the monolithic view of its relationship with learning styles. System, 61, 55-64.

O'Sullivan, Í., \& Chambers, A. (2006). Learners' writing skills in French: Corpus consultation and learner evaluation. Journal of Second Language Writing, 15(1): 49-68.

Römer, U. (2008). Corpora and language teaching. In A. Lüdeling, \& M. Kyto (Eds.), Corpus linguistics: An international handbook (Vol. 1) (pp. 112-130), Berlin: Mouton de Gruyter.

Sun, Y.-C. (2007). Learner perceptions of a concordancing tool for academic writing. Computer Assisted Language Learning, 20(4), 323-343

Thurstun, J., \& Candlin, C. (1997). Exploring academic English: A workbook for student essay writing. Sydney: NCELTR.

Todd, R. (2001). Induction from self-selected concordances and self-correction. System 29(1), 91-102.

Tono,Y., Satake, Y., \& Miura, A. (2013). The effects of using corpora on revision tasks in L2 writing with coded error feedback. ReCALL, 26(2), 147-162.

Ucar, S., \& Yükselir, C. (2015). The effect of corpus-based activities on verb-noun collocations in EFL classes. Turkish Online Journal of Educational Technology - TOJET, 14 (2), 195205.

Varley, S. (2009). I'll just look that up in the concordancer: Integrating corpus consultation into the language learning environment. Computer Assisted Language Learning, 22(2), $133-152$.

Vyatkina, N. (2016). Data-driven learning of collocations: learner performance, proficiency, and perceptions, Language Learning \& Technology, 20(3), 159-179. 
Walters, J., \& Wolf, Y. (1996). Language awareness in non-native writers: metalinguistic judgements of need for revision. Language Awareness, 5 (1), 3-25.

Yoon, H., \& Hirvela, A. (2004). ESL student attitudes toward corpus use in L2 writing. Journal of Second Language Writing, 13, 257-283.

Yoon, H., \& Jo, J. W. (2014). Direct and indirect access to corpora: An exploratory case study comparing students' error correction and learning strategy use in L2 writing. Language Learning \& Technology, 18(1), 96-117.

\section{Copyrights}

Copyright for this article is retained by the author(s), with first publication rights granted to the Journal.

This is an open-access article distributed under the terms and conditions of the Creative Commons Attribution license (CC BY-NC-ND) (http://creativecommons.org/licenses/by-nc-nd/4.0/). 